\title{
THE RELATION OF PLASMA AND BILIARY CHOLESTEROL TO BILE ACID SYNTHESIS IN MAN *
}

\author{
By R. S. ROSENFELD AND LEON HELLMAN \\ (From the Sloan-Kettering Institute for Cancer Research, New York, N. Y.)
}

(Submitted for publication February 16, 1959; accepted April 9, 1959)

Bile is an important excretory route of steroids since it contains cholesterol and bile acids which are derived from cholesterol. That cholic acid is formed from cholesterol was demonstrated by Bloch, Berg and Rittenberg over a decade ago (1). Other workers have confirmed this finding in animals (2-6) and the conversion has also been demonstrated in the human $(7,8)$. Intermediates involved in this transformation have been extensively studied and reviewed by Bergström and Borgström $(9,10)$ and these workers have more recently reported on the stereochemical course of the transformation of cholesterol to cholic acid (11). This investigation deals with the dynamic aspects of the conversion of cholesterol of both endogenous and exogenous origins to cholic acid in man.

Cholesterol-4- $\mathrm{C}^{14}$ and sodium acetate- $\mathrm{H}^{3}$ were fed to one subject, and sodium acetate- $2-\mathrm{C}^{14}$ was administered to a second subject; both had complete bile fistulas. It was found that orally ingested cholesterol and biosynthetic cholesterol mixed indistinguishably in the plasma after a short equilibration period. Plasma and biliary cholesterol had the same specific acivity and were in isotope equilibrium with the pool which served as the precursor of cholic acid.

\section{EXPERIMENTAL}

Clinical material. The subjects were hospitalized on a metabolic ward where complete collections of urine, feces and bile could be made. Subject A was a 58 year old white man who had an external bile fistula established surgically for the relief of a bile duct obstruction due to carcinoma of the pancreas. The completeness of the fistula was demonstrated by retrograde cholecystiography

* This investigation was supported by a grant from the American Cancer Society; Contract AT30-1 910 with the United States Atomic Energy Commission; a research grant ( $\mathrm{H}-2157)$ from the National Heart Institute; and a research grant (CY-3207) from the National Cancer Institute, National Institutes of Health, United States Public Health Service. and acholic stools. At the time of the study he was in good clinical condition; the daily volume of bile drained through the fistula varied from 630 to $850 \mathrm{ml}$. This patient received approximately $2 \mathrm{Gm}$. of bile salts daily. Subject B was a 60 year old white man in whom the bile fistula was established during an operative attempt to resect a carcinoma of the pancreas. The completeness of the fistula was demonstrated by acholic stools. At the time of the study this patient was in fair clinical condition; he was slightly jaundiced and the serum bilirubin was $1.60 \mathrm{mg}$. per cent; other liver function tests were normal with a cephalin flocculation of $1+$ and a thymol turbidity of 0.6 . The output of bile varied from 520 to $650 \mathrm{ml}$. daily. Subject A received $15.4 \mathrm{mg}$. of cholesterol$4-\mathrm{C}^{14}\left(5.9 \mu \mathrm{c}\right.$. per mg.) and $700 \mu \mathrm{c}$. of sodium acetate $-\mathrm{H}^{3}$. Subject B received $309 \mu$ c. of sodium acetate- $2-C^{14}$. All labeled material was given by mouth after an overnight fast.

Isolation procedures. Blood and bile were collected at predetermined time intervals from each patient; feces obtained in a 24 hour period were combined. Free and ester cholesterol were isolated from plasma by a method described previously (12). Bile samples were acidified with sulfuric acid to $\mathrm{pH} 1$ and continuously extracted with ether for 48 hours; the ether solution was extracted with 5 per cent sodium hydroxide. The ether solution was then concentrated and the residue was chromatographed on alumina. Cholesterol was eluted by petroleum etherbenzene mixtures and after recrystallization from acetone, melted at 148 to $149^{\circ}$. The aqueous alkaline solution was treated with carbon dioxide until a copious precipitate of sodium carbonate appeared in the flask. Water was added in sufficient quantity to dissolve the precipitate and the solution was extracted with ether to remove phenolic material. The residual alkaline solution was acidified with hydrocholoric acid and, after evolution of gas, extracted with ethyl acetate. The ethyl acetate solution was concentrated to obtain the crude conjugated bile acid fraction. This material was dissolved in 10 per cent potassium hydroxide and refluxed for 16 hours. After cooling, the alkaline solution was washed with ether. Acidification of the alkaline layer followed by ethyl acetate extraction yielded a solution of crude bile acids which partially crystallized on removal of the solvent. This material was dissolved in 1:1 methanol-ethyl acetate and was esterified with diazomethane in ether solution. Concentration of this solution gave an oil which was chromatographed on silica gel (13). Two principal fractions were obtained from the column. Material eluted with ether was shown by infrared spectrometry to be a 
mixture of methyl deoxycholate and methyl chenodeoxycholate. Crystalline methyl cholate was obtained from the acetone-ether $(1: 1)$ eluates. This material had an infrared spectrum identical with that of authentic methyl cholate. Recrystallization from ethanol-petroleum ether yielded methyl cholate, melting point 156 to $157^{\circ}$; the melting point did not change on admixture with authentic material.

Cholic acid content of whole bile was quantitatively determined by the method of Irvin, Johnston and Kopala (14).

Feces were homogenized with $500 \mathrm{ml}$. of acetone and centrifuged; the supernatant was decanted. This extraction procedure was repeated three times. The combined acetone supernatants were concentrated and then saponified by refluxing for three hours in 20 per cent alcoholic potassium hydroxide. The nonsaponifiable material was extracted with petroleum ether and the oil which was obtained was chromatographed on alumina for the isolation of cholesterol and coprostanol.

The radioactivity of cholesterol was measured by depositing cholesterol digitonide on stainless steel planchets from an acetone-alcohol slurry (12). Methyl cholate and coprostanol were melted onto the planchets. Carbon-14 activity of these samples containing both radiocarbon and tritium was determined in a windowless flow-gas counter with the tritium beta particles screened out by aluminum foil (15). Tritium activity was determined by converting the samples to hydrogen gas which was counted in a Geiger tube (16). The radiocarbon counting procedure was calibrated against a National Bureau of Standard $\mathrm{C}^{14}$ standard and the carbon radioactivity data are expressed in terms of distintegrations per minute per millimole $(\mathrm{DPM} / \mathrm{mMole})$. The tritium radioactivity data are given in terms of counts per minute per millimole of hydrogen $\left(\mathrm{cpm} / \mathrm{mMole} \mathrm{H}_{2}\right)$.

\section{RESULTS AND DISCUSSION}

Figures 1 and 2 demonstrate the biosynthesis of plasma and biliary cholesterol from sodium acetate in Subjects $A$ and $B$, respectively. The maximum radioactivity of plasma free and biliary cholesterol was attained at three to four hours after administration of the dose. The specific activity of the early samples of cholesterol isolated from bile exceeded that of plasma cholesterol by about 10 per cent. The lower plasma values may be explained by the dilution of newly synthesized labeled cholesterol by the pre-existing pool of nonradioactive sterol in the plasma; the difference between the radioactivity of plasma and biliary cholesterol disappeared after two days. Bile cholesterol which drained directly to the exterior did not undergo this dilution and was perhaps more representative of newly synthesized liver cholesterol. Rosenman

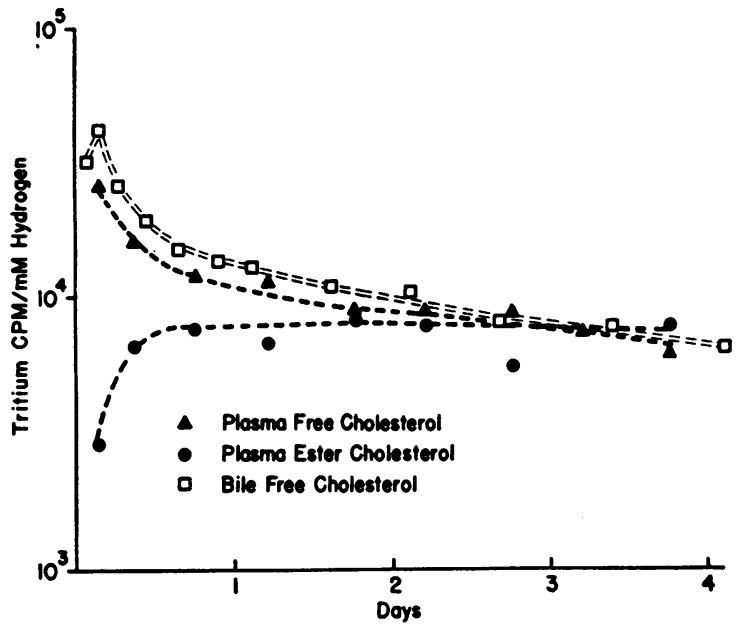

Fig. 1. Incorporation of Acetate-2-H H $^{3}$ into Plasma and Biliary Cholesterol

and associates $(17,18)$ have also pointed out that the cholesterol which appears in the bile of their experimental animals represents newly synthesized sterol. A similar elevation in the specific activity of biliary cholesterol as compared with plasma cholesterol was reported by Gould and coworkers who administered labeled acetate to dogs with bile fistulas (19).

The simultaneous appearance of radioactivity in bile and plasma cholesterol and the similarity of the specific activity curves indicate that biliary and plasma cholesterol are in rapid isotope equilibrium with a common pool. As would be expected, liver cholesterol also forms part of this common pool since it has been found from human

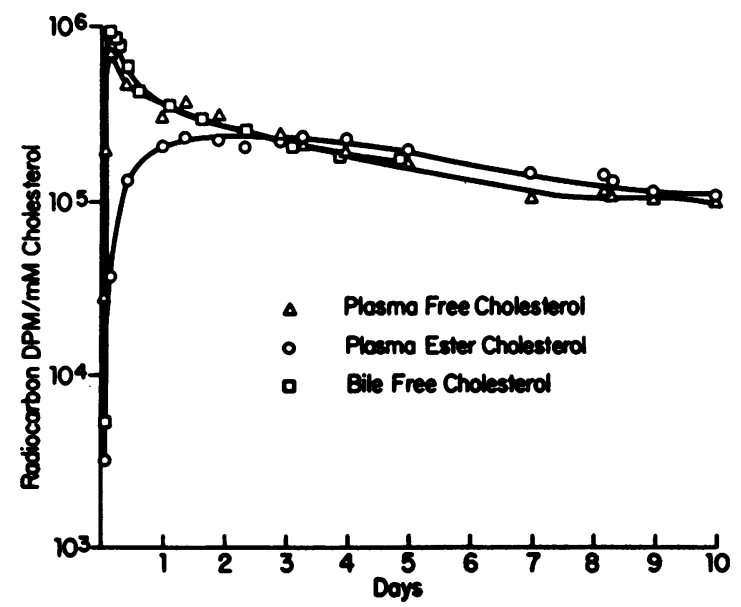

Fig. 2. Incorporation of Acetate-2-C ${ }^{14}$ into Plasma and Biliary Cholesterol 


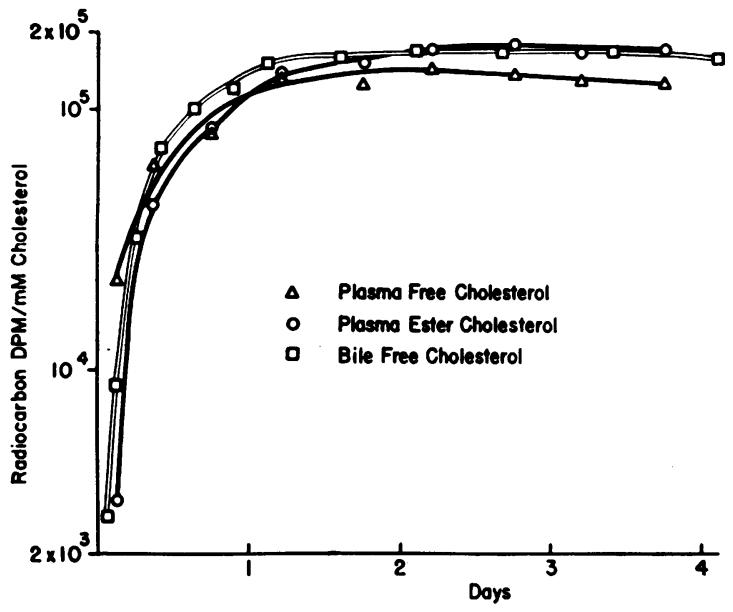

Fig. 3. Incorporation of Oral Cholesterol-4-C ${ }^{14}$ into Plasma and Biliary Cholesterol

biopsy material that hepatic and plasma cholesterol have the same specific activity after administration of radioactive sodium acetate (20).

The cholesterol ester of plasma has an initially low radioactivity (Figures 1 and 2 ) which gradually increases so that its specific activity curve intersects those of the plasma and biliary free cholesterol at about two and one-half days (21).

The interrelations of plasma and biliary cholesterol derived from orally ingested cholesterol$4-\mathrm{C}^{14}$ in Subject $\mathrm{A}$ are shown in Figure 3. The specific activities of plasma free, ester and biliary cholesterol are initially at low levels and reach a maximum at one to two days (15). This suggests that the absorption of cholesterol from the intestine is relatively prolonged with a gradual rise in specific activity as the radioactive cholesterol enters the circulation. This conclusion is substantiated by direct measurement of cholesterol absorption in human lymph (22). It should be noted in Figure 3 that the specific activity of plasma free cholesterol is initially higher than biliary cholesterol. This occurs since newly absorbed labeled cholesterol is directly delivered to the circulation via the lymph, whereas hepatic and biliary cholesterol become labeled only after mixing with circulating sterol.

The plasma specific activity curves measured in subjects with complete biliary fistulas are remarkably similar in slope to those measured in intact subjects $(15,21)$. This similarity extends as far as 10 days (Figure 2) after administration of the dose and suggests that the biliary

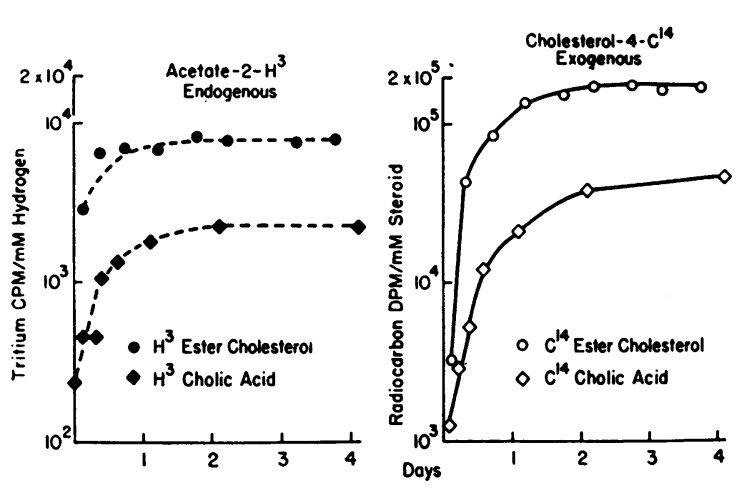

Fig. 4. Simultaneous Incorporation of Acetate and Cholesterol into Bile Acid and Plasma Ester ChOlesterol

loss of cholesterol occurring under the conditions of this experiment does not result in either increased biosynthesis or absorption of cholesterol in response to the potential diminution of the size of the common cholesterol pool. Had such changes occurred, a more rapid rate of fall-off in specific activity would have been expected due to the increased influx of unlabeled cholesterol.

Figure 4 compares the radioactivity of plasma ester cholesterol with that of cholic acid in Subject $A$. The parallel increase of tritium radioactivity in cholic acid and ester cholesterol suggests that both these substances are derived from the common sterol pool represented by the plasma, biliary and hepatic free cholesterol. The similarity in shape of the $\mathrm{C}^{14}$-radioactivity curves derived from dietary cholesterol further suggests the precursor role of plasma free cholesterol. The specific activities of plasma ester cholesterol are considerably higher than corresponding values for cholic acid throughout the period of observation. This is to be expected since the specific activity of cholic acid was undoubtedly lowered by dilu-

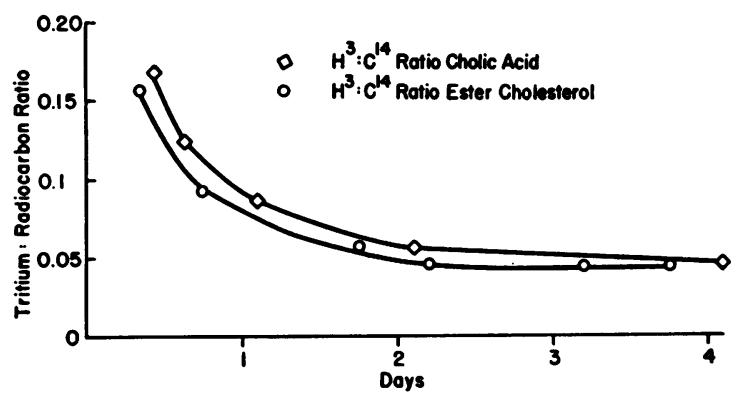

Fig. 5. Tritium : Radiocarbon Ratios in Ester Cholesterol and Cholic Acid 
TABLE I

$C^{14}$-radioactivity in bile and in methyl cholate

(Subject A)

\begin{tabular}{ccccccc}
\hline \hline $\begin{array}{c}\text { Duration } \\
\text { of collection }\end{array}$ & $\begin{array}{c}\text { Volume } \\
\text { of bile }\end{array}$ & DPM* & $\begin{array}{c}\text { Cholate } \\
\text { in bile }\end{array}$ & $\begin{array}{c}\text { DPM/mg.t } \\
\text { methyl cholate }\end{array}$ & $\begin{array}{c}\text { DPM* of } \\
\text { methyl cholate }\end{array}$ & $\begin{array}{c}\text { Per cent } \\
\text { radioactivity } \\
\text { methyl cholate }\end{array}$ \\
\hline hrs. & $m l$. & & & & & \\
2 & 60 & 16.3 & 311 & 11.5 & 3.60 & 22.0 \\
4 & 86 & 44.2 & 432 & 15 & 6.50 & 14.7 \\
6 & 133 & 97.4 & 460 & 60 & 27.6 & 23.4 \\
6 & 257 & 96.5 & 290 & 82 & 55.7 & 52.2 \\
6 & 160 & 106 & 557 & 100 & 63.5 & 56.6 \\
6 & 254 & 112 & 576 & 110 & 19.6 & 20.0 \\
6 & 163 & 98 & 166 & 118 & 8.3 & 33.5 \\
6 & 98 & 24.7 & 66.5 & 125 & & \\
\hline
\end{tabular}

* Disintegrations per minute $\times 10^{-3}$.

+ Measured by the method of Irvin, Johnston and Kopala (14).

¥ Specific activity of isolated material.

tion with the bile salts administered as replacement therapy; however, it is not possible to state unequivocally that this is the only reason for the difference. Despite this difference, the precursorproduct relationship of the pool represented by plasma cholesterol and cholic acid can be seen unequivocally in Figure 5 where the isotope ratio of tritium to $\mathrm{C}^{14}$ is identical in plasma ester cholesterol and cholic acid. These data indicate that cholic acid is derived from cholesterol of both biosynthetic and exogenous origin.

In Table I, 15 to 56 per cent of the radioactivity in bile was present as cholic acid as measured by the method of Irvin and co-workers (14). These figures are lower than the values for biliary cholic acid reported by Siperstein and Murray (8). However, their subject was in good health except for the bile fistula and the cholesterol tracer dose was administered intravenously. These factors might account for the differences.

The radioactivity of cholesterol and coprostanol isolated from the feces of Subject A during the first day was compared with that of plasma free cholesterol at 24 hours (Table II). The carbon-

TABLE II

Radioactivity of fecal sterols after one day (Subject $A$ )

\begin{tabular}{lccc}
\hline \hline & Coprostanol & $\begin{array}{c}\text { (Feces) } \\
\text { choiesterol }\end{array}$ & $\begin{array}{c}\text { (Plasma free) } \\
\text { cholesterol }\end{array}$ \\
\hline $\mathrm{T}^{*}$ & 7.7 & 12.8 & 11.0 \\
$\mathrm{C}^{14} \dagger$ & 10.0 & 0.03
\end{tabular}

* Disintegrations per minute (DPM) per millimole of hydrogen $\times 10^{-3}$.

+ DPM per millimole $\times 10^{-7}$.
14 specific activities of the fecal sterols are 200 times higher than plasma cholesterol-C ${ }^{14}$ which would be expected if a portion of orally ingested, highly radioactive sterol escaped absorption. The correspondingly high $\mathrm{C}^{14}$ activity in coprostanol shows that it was formed from cholesterol in the intestine. This observation is supported by experiments which demonstrate the conversion of cholesterol to coprostanol both in the intestine and in incubation studies with feces (23). However, the tritium specific activity of fecal cholesterol is quite similar to that of plasma free cholesterol. Because of the presence of the bile fistula, cholesterol could only enter the intestine by way of the mucosa. The data on this patient as well as other observations (24) suggest that plasma cholesterol secreted through the intestinal mucosa serves as an important precursor for fecal sterols.

Several important relationships of the various steroid pools of the body have been clarified by these data. Plasma, bile and liver cholesterol have the same specific activity under equilibrium conditions and, therefore, the behavior of all three components will probably be involved in any situation in which there is a change in only one member of this pool. The enterohepatic circulation of biliary cholesterol is a pathway through which endogenously synthesized cholesterol can assume the character of dietary sterol. If some qualitative characteristic of dietary sterol, such as the physicochemical form in which it is absorbed, is related to the atherogenecity of cholesterol, then endogenous cholesterol should be considered in the same light as cholesterol of dietary origin. 


\section{SUMMARY}

Sodium acetate- $\mathrm{H}^{3}$ and cholesterol-4- $\mathrm{C}^{14}$ were administered orally to one subject and sodium acetate-2-C $\mathrm{C}^{14}$ was given to a second subject; both had complete biliary fistulas. Cholesterol was isolated from the plasma and bile and cholic acid (as methyl cholate) was obtained from the bile. Sufficient samples were isolated to permit the construction of rate curves so that the dynamic behavior of these substances could be compared.

It has been found that biliary cholesterol and plasma free cholesterol are parts of the same metabolic pool. Evidence is also presented which shows that cholic acid is derived from cholesterol of endogenous and dietary origin. After ingestion of cholesterol-4-C ${ }^{14}$, from 10 to 50 per cent of the $\mathrm{C}^{14}$-radioactivity in bile was accounted for as cholic acid.

Cholesterol and coprostanol were also isolated from the feces and evidence has been presented to show that a significant portion of the fecal sterols are derived from plasma cholesterol and arise through intestinal excretion.

\section{ACKNOWLEDGMENT}

The support and interest of Dr. T. F. Gallagher in this investigation are gratefully acknowledged.

\section{REFERENCES}

1. Bloch, K., Berg, B., and Rittenberg, D. Biological conversion of cholesterol to cholic acid. J. biol. Chem. 1943, 149, 511.

2. Zabin, I., and Barker, W. F. The conversion of cholesterol and acetate to cholic acid. J. biol. Chem. 1953, 205, 633.

3. Siperstein, M. D., and Chaikoff, I. K. C Cholesterol: excretion of carbons 4 and 26 in feces, urine, and bile. J. biol. Chem. 1952, 198, 93.

4. Siperstein, M. D., Jayko, M. E. Chaikoff, I. L., and Dauben, W. G. Nature of the metabolic products of $\mathrm{C}^{14}$-cholesterol excreted in bile and feces. Proc. Soc. exp. Biol. (N. Y.) 1952, 81, 720.

5. Siperstein, M. D., Harold, F. M., Chaikoff, I. L., and Dauben, W. G. C Ch-cholesterol. VI. Biliary end-products of cholesterol metabolism. J. biol. Chem. 1954, 210, 181.

6. Ekdahl, P. H., and Sjövall, J. Formation of bile acids from cholesterol in the rabbit. Acta physiol. scand. 1955, 34, 329.

7. Rosenfeld, R. S., Hellman, L., and Gallagher, T. F. Plasma and biliary sterol metabolism in man. Fed. Proc. 1955, 14, 271.
8. Siperstein, M. D., and Murray, A. W. Cholesterol metabolism in man. J. clin. Invest. 1955, 34, 1449.

9. Bergström, S. Formation and metabolism of bile acids. Record chem. Progr. 1955, 16, 63.

10. Bergström, S., and Borgström, B. Metabolism of lipides. Ann. Rev. Biochem. 1956, 25, 177.

11. Bergström, S., Lindstredt, S., Samuelson, B., Corey, E. J., and Gregoriou, G. A. The stereochemistry of $7 \alpha$-hydroxylation in the biosynthesis of cholic acid from cholesterol. J. Amer. chem. Soc. 1958, 80, 2337.

12. Rosenfeld, R. S., Hellman, L., Considine, W. J., and Gallagher, T. F. Isolation of radioactive cholesterol from plasma. J. biol. Chem. 1954, 208, 73.

13. Wootton, I. D. P. Studies in the bile acids. I. A method of separation and identification. Biochem. J. 1953, 53, 85.

14. Irvin, J. L., Johnston, C. G., and Kopala, J. A photometric method for the determination of cholates in bile and blood. J. biol. Chem. 1944, 153, 439.

15. Hellman, L., Rosenfeld, R. S., Eidinoff, M. L., Fukushima, D. K., Gallagher, T. F., Wang, C., and Adlersberg, D. Isotopic studies of plasma cholesterol of endogenous and exogenous origins. J. clin. Invest. 1955, 34, 48.

16. Eidinoff, M. L. Internal gas counting of radioactive carbon and hydrogen in A. I. E. E. Second Annual Joint Conference on Electronics in Nucleonics and Medicine, (A. I. E. E. Special Publication No. 33). New York, American Institute of Electrical Engineers, 1950, p. 65.

17. Rosenman, R. H., and Shibata, E. Effect of age upon hepatic synthesis of cholesterol in the rat. Proc. Soc. exp. Biol. (N. Y.) 1952, 81, 296.

18. Rosenman, R. H., Byers, S. O., and Friedman, M. The mechanism responsible for the altered blood cholesterol content in deranged thyroid states. J. clin. Endocr. 1952, 12, 1287.

19. Gould, R. G., Campbell, D. J., Taylor, C. B., Kelly, F. B., Jr., Warner, I., and Davis, C. B., Jr. Origin of plasma cholesterol using $\mathrm{C}^{14}$. Fed. Proc. 1951, 10, 191.

20. Hellman, L., and Rosenfeld, R. S. Unpublished observations.

21. Hellman, L., Rosenfeld, R. S., and Gallagher, T. F. Cholesterol synthesis from $\mathrm{C}^{14}$-acetate in man. J. clin. Invest. 1954, 33, 142.

22. Hellman, L., Frazell, E. L., and Rosenfeld, R. S. Direct measurement of cholesterol absorption via the thoracic duct in man (abstract). J. clin. Invest. 1958, 37, 900.

23. Rosenfeld, R. S., Fukushima, D. K., Hellman, L., and Gallagher, T. F. The transformation of cholesterol to coprostanol. J. biol. Chem. 1954, 211, 301.

24. Hellman, L., Rosenfeld, R. S., Insull, W., Jr., and Ahrens, E. H., Jr. Intestinal excretion of cholesterol: A mechanism for regulation of plasma levels (abstract). J. clin. Invest. 1957, 36, 898. 